Mehmet Akif Ersoy Üniversitesi Fen Bilimleri Enstitüsü Dergisi 6(1): 6-10 (2015)

The Journal of Graduate School of Natural and Applied Sciences of Mehmet Akif Ersoy University 6(1): 6-10 (2015)

Derleme Makale / Review Paper

\title{
Burdur Gölü Havzasının Çevresel Açıdan İrdelenmesi
}

\author{
Latif Gürkan KAYA ${ }^{1}$, Cengiz YÜCEDAĞ ${ }^{1 *}$, Özge DURUŞKAN \\ ${ }^{1}$ Mehmet Akif Ersoy Üniversitesi Mühendislik Mimarlık Fakültesi, Burdur \\ Geliş Tarihi (Received): 03.12.2015, Kabul Tarihi (Accepted): 16.12.2015 \\ $\square$ Sorumlu Yazar (Corresponding author)*: cyucedag@mehmetakif.edu.tr \\ (C) +902482132785 且 +902482132704
}

$\overline{O ̈ Z}$

Çevre sorunları, günümüzün en önemli yaşamsal konuları arasında yer almaktadır. Özellikle Sanayi Devrimi sonrasında dünyanın ekolojik dengesi üzerine artan bilinçsiz antropojenik aktiviteler ulusal ve uluslararası anlamda birçok olumsuz sonucu beraberinde getirmektedir. Bu çerçevede, Türkiye'nin altıncı büyük göl havzası olan Burdur Gölü Havzası'nın ekolojisinin ve özellikle alanın endemik türü olan dik kuyruğun korunması amacıyla bu çalışmada, ulusal ve uluslararası literatüre ve ayrıca bölgedeki gözlemlere dayanarak havzayı etkileyen etmenler ve olası çözüm öneriler üzerinde durulmuştur.

Anahtar Kelimeler: Burdur gölü, çevre sorunları, ekoloji

\section{Environmental Investigation in Burdur Lake Basin}

\begin{abstract}
Environmental problems are among the most vital issues of the today's world. Especially after the Industrial Revolution, increasing unconscious anthropogenic activities on the ecological balance of world have brought many negative consequences at the national and international level. In this frame, in this study factors affecting the Burdur lake basin and possible solutions have been focused in order to be conserved the ecology and especially white-headed ducks (endemic species) of the basin, the six largest lake basin of Turkey, based on national and international literature and also observations in the region.
\end{abstract}

Keywords: Burdur lake, environmental problems, ecology

\section{GíRiş}

Günümüzde çevre sorunları, dünya ve ülkemizin en önemli konuları arasında yer almaktadır. Özellikle Sanayi Devrimi sonrasında dünyanın ekolojik dengesi üzerine artan bilinçsiz antropojenik aktiviteler ulusal ve uluslararası anlamda birçok olumsuz sonucu beraberinde getirmektedir. Çevresel sorunların hızlı ar- tışı, 1970'li yıllardan itibaren uluslararası ölçekte birçok toplantının yapılmasına ve çeşitli sözleşme ve bildirgelerin yayımlanmasına neden olmuştur. Bu anlamda, 1971 yılında birçok ülke tarafından imzalanan Ramsar Sözleşmesi önemli doğal kaynaklarımızdan biri olan sulak alanların korunması yönünde atılmış önemli bir adımdır. 
Türkiye Ramsar Sözleşmesi'ni 1993 yılında imzalayarak belirlediği sulak alanları koruma altına almaya karar vermiştir. Türkiye'de 19'u önemli olmak üzere 250 'nin üzerinde sulak alan bu sözleşme kapsamına alınmıştır. Burdur Gölü, Ramsar Sözleşmesi kapsamına alınan Türkiye'nin 19 önemli sulak alanından biridir. 1994 yılında Burdur Gölü'nün yaklaşık \%50'si (12.600 ha) Ramsar Sözleşmesi listesine alınmıştır (Yiğitbaşıŏlu ve Uğur, 2006). Bu sözleşme kapsamına alınmasına ve birçok kuş türü için önemli bir sulak alan olmasına rağmen, Burdur Gölü ve çevresinin koruma-kullanma dengesi yüksek oranlarda bozulmuş ve bilinçsiz kullanma da ekolojik etkilenme derecesini olumsuz yönde artırmıştır (Çetin ve ark., 2013). Ayrıca, 1975-2010 yılları arasında Burdur gölünün su yüzey alanı $\% 64,5$ oranında küçülmüş ve yine göl seviyesi $11.86 \mathrm{~m}$ azalmıştır (Yıldırım ve Uysal, 2011).

Gerçekte sulak alanlar, yeryüzünün en zengin ve en üretken ekosistemlerini oluşturmaktadır. Bu alanlar yöre insanlarına ve ülkenin geneline geniş yelpazede hizmet veren oldukça karmaşık doğal sistemlerdir ve yeryüzündeki başka hiçbir ekosistemle karşılaştırılmayacak ölçüde işlev ve değerlere sahiptir (Anonim, 2015). Türkiye'nin altıncı büyük gölü olan Burdur Gölü havzasının ekolojisinin ve özellikle alanın endemik türü olan dik kuyruğun korunması amacıyla bu çalışmada, ulusal ve uluslararası literatüre ve ayrıca bölgedeki gözlemlerimize dayanarak Burdur gölü havzasını etkileyen etmenler ve olası çözüm öneriler üzerinde durulmuştur.

\section{BURDUR GÖLÜ HAVZASININ TANITIMI}

Göller Bölgesi'nin en büyük gölleri arasında yer alan Burdur Gölü Havzası, suları denize ulaşmayan yani kapalı bir havzadır. Yağışlarla havzaya düşen su, havzanın en derin yeri olan Burdur Gölü çanağında toplanmakta ve yüzeysel akışlar ve yeraltı suyu akımı ile boşalımı ise, göl alanından buharlaşma yoluyla gerçekleşmektedir. 3264 km² alana sahip Burdur Gölü Havzası, Burdur ve Isparta il sınırları içerisinde yer alır. Burdur Merkez, Kemer, Keçiborlu ve Tefenni ilçeleri ile Isparta'nın Keçiborlu ve kısmen Gönen ilçesi havza sınırları içerisinde yer almaktadır. Burdur Gölü Havzası, genel hatlarıyla 12 alt havzadan oluşur. Bu alt havzalar içinde Bozçay'ın havzası en büyüğü olup diğer tüm alt havzaların alanlarının toplamından daha geniş alan kaplamaktadır (Gülle ve ark., 2008; Ataol, 2010).

Burdur Havzasının ikliminde Akdeniz iklimi ile Karasal iklim arasında geçiş özeliğinin egemen olduğu görülür. Buna göre, yaz mevsimi sıcak ve kurak, kış mevsimi ise oldukça soğuk geçmektedir. Yıllık ortalama sıcaklık $13 \mathrm{C}^{\circ}$ ve yıllık ortalama yağış miktarı 405 mm'dir (Yiğitbaşıoğlu ve Uğur, 2010).

Havzanın ortalama rakımı 843 m'dir. Gölün uzunluğu 34 $\mathrm{km}$ ve genişliği 9 km'dir. Göl suyu binde 24 oranında tuzludur. Burdur Gölü oluk şeklindeki tektonik bir çöküntünün suyla dolmasıyla oluşan tektonik bir göldür. Bu türdeki göller tektonik bir sarsıntı sonucu oluşan çukurları suyla dolmasıyla oluşur. Güneybatı ve kuzeydoğu yönlerinde ise alüvyal birikim nedeniyle tuzlu bataklıklar bulunmaktadır. Göl suyundaki tuzluluk ve arsenik nedeniyle gölde yaşayan su bitkileri ve balık gibi canlı türü sayısı ve çeşitliliği az olmakla beraber gölde endemik türler yaşamaktadır. Burdur gölü havzasının endemik bitki türü sayısı 49 ve endemizm oranı\%10,53'tür. Bu endemik bitki türleri arasında Genista burdurensis gibi Burdur'un adını taşıyan ve dünya genelinde sadece Burdur'a has endemikleri de vardır. Havzada bitki türü sayısı bakımından en zengin familya Compositae (Asteraceae) familyası ve en zengin cins ise Centaurea L. cinsidir (Çetin ve ark., 2013; Karataş, 2013).

Burdur Gölü'nde Aphanius anatoliae sureyanus ve Pseudophoxinus burduricus sp. olmak üzere iki endemik balık türü yaşamaktadır. Burdur Türkiye kuş türlerinin \%57'sini barındırmaktadır. Burdur Gölü’nün biyocoğrafik açıdan en büyük önemi nesli dünya çapında tehlikede olan Dikkuyruk Ördek'in (Oxyura leucocephala) dünyadaki popülasyonunun yaklaşık \%70'inin gölde bulunmasından gelmektedir (Güçlü ve ark., 2007; Karataş, 2013; Küçük ve ark., 2013). Yukarıda bahsedilen flora ve fauna değerleri ile Burdur gölü havzası kuş gözlemciliği ve peyzaj aktiviteleri için son derece elverişli bir konuma sahiptir. 


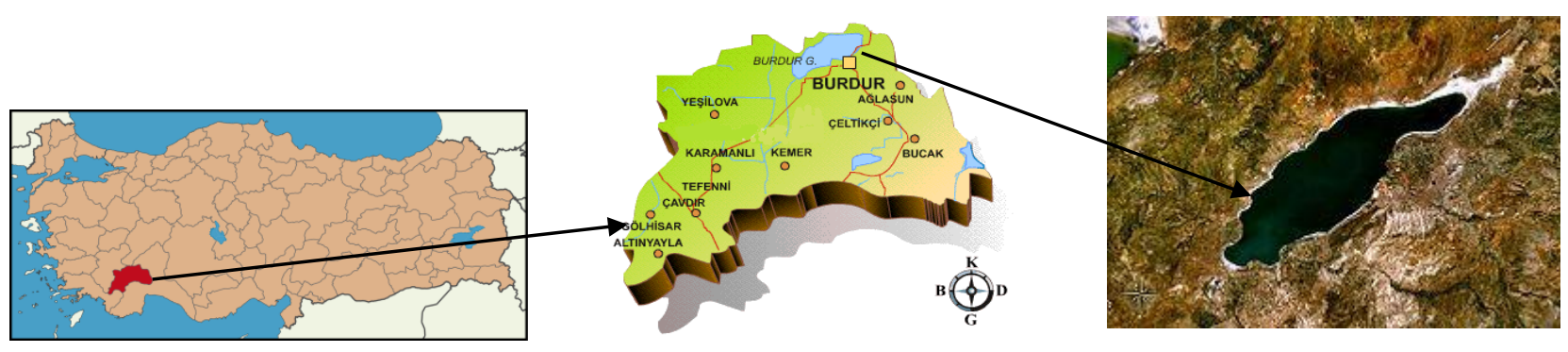

Şekil 1. Çalışma alanı

\section{BURDUR GÖLÜ HAVZASINI TEHDIT EDEN ETMEN- LER}

\section{Barajlar}

Son yıllarda gölü besleyen akarsuların göle ulaşmaması ve gölün buharlaşma ile su kaybetmesi hem gölün su seviyesinin düşmesine hem de tuzluluk oranının artması sonucunu ortaya çıkarmıştır. Su seviyesindeki düşüşün en önemli nedeni tarımsal sulama amaçlı plansız bir şekilde gölü besleyen akarsular üzerine baraj ve göletlerin inşa edilmesidir. Havzada gölü besleyen en büyük akarsu gölün güneybatısındaki Bozçay'dır. Diğer akarsular ise Kıravgaz, Kurna, Çerçin, Lengüme dereleri ile kuzeydoğuda Keçiborlu'dan gelen Adalar Çayı'dır. Akarsular dışında Senir beldesi yakınlarındaki gür kaynak göle su sağlamaktadır. Ancak, bu kaynağın suları da Burdur Şehri'ne içme suyu sağlanması amacıyla kaynaktan alınarak iki boru yardımıyla gölün üstünden geçirilerek Burdur içme suyu şebekesine bağlanmıştır (Yiğitbaşıoğlu ve Uğur, 2005; Ataol, 2010; DSì, 2015).

Göldeki tuzluluk oranına rağmen gölde yaşamaya adapte olmuş Aphanius sureyanus dünyada sadece Burdur Gölü'nde yaşamakta ve gölün yok olmasıyla birlikte nesli tehlike altına girmektedir. Bununla birlikte nesli küresel ölçekte tehlike altında olan dikkuyruk ördeğinin gölün seviyesindeki düşüşün etkilemesinden endişe edilmektedir.

\section{Endüstriyel Atıklar}

Atık miktarı 214 It/sn olan şeker fabrikası göl suyunun asitlik derecesinin artmasına neden olmaktadır (Kiziroğlu ve ark., 1995). Burdur Gölü havzasında yer alan şeker fabrikası göle en fazla endüstriyel atık karışmasına sebep olan sanayi kuruluşu olarak görülmektedir. Bunun yanında kanalizasyon atıklarının gölü kirletmesinin önlenmesi için yapımı tamamlanan Burdur Atık Su Arıtma Tesisi'nin tam kapasite çalıştırılmaması da Burdur Gölü'nü bir fosseptik çukur haline dönüşmesine sebep olmaktadır. Diğer taraftan, Isparta Süleyman
Demirel Organize Sanayi Bölgesi'nin arıtma tesisi bulunmakla birlikte, Burdur Organize Sanayi Bölgesi'nin herhangi bir arıtma tesisi bulunmamaktadır (Anonim, 2013). Sonuçta göl suyu oksijeni azalmakta ve tabandan abiyotik bir ortam yükselmektedir.

\section{Tarımsal Faaliyetler}

Havzadan geçip, gölü besleyen irili ufaklı dere ve çaylarla gerçekleşen yüzeysel akışla taşınan böcek öldürücü kimyasal madde ve sedimanlar da gölün kirlenmesine yol açmaktadır. Bunların dışında gölü doğrudan doğruya çevreleyen birincil derecedeki zonlarda bulunan 10-15 irili ufaklı yerleşim biriminden kaynaklanan kirleticiler de göle intikal etmektedir. Göle ulaşan akarsularda bol miktarda tarım ilacı ve yapay gübre taşımaktadırlar.

Sulama için doğal döngüsünden çıkarılan suyun büyük kısmı ilkel sulama yöntemleriyle israf edilmektedir. Göldeki su azaldıkça su kalitesi bozulacağı gibi göl havzasının iklim koşullarında karasallık yönünde değişim görülecek, kış mevsiminde daha da düşecek olan gece sıcaklıkları nedeniyle özellikle meyvecilik zarar görecektir. Burdur kent sınırındaki ovalarda 72 adet sulama kooperatifi, 374 adet işletme sondaj kuyusu ile 12405 ha net, 14663 ha brüt arazi yeraltından sulanmaktadır (Anonim, 2009). Sonuçta tarım için gölden (dolaylı olarak) alınan su nedeniyle uzun vadede zarar görecek olan yine tarım olacaktır (Ataol, 2010). Arazi kullanımındaki yanlışlıklar ve yanlış planlamalar da havzada çevresel sorunlara neden olmaktadır (Yiğitbaşıŏlu ve Uğur, 2010).

Burdur Gölü ve çevresindeki tarım alanlarında ekolojik ve çevresel koşullara uygun olmayan ve su isteği yüksek tarımsal ürünlerin yetiştirilmesi, yoğun kültür çalışmaları ile toprağın besin maddesi açısından fakirleştirilmesi gibi yanlış ve bilinçsizce yapılan tarımsal faaliyetler bütüncül ekosistem üzerinde olumsuz etkiler meydana getirmektedir (Gül ve ark., 2015). 


\section{Kent Alanının Genişlemesi}

2006 yılında Mehmet Akif Ersoy Üniversitesi'nin açılması şehir nüfusunun artışında önemli bir etkiye sahiptir. Üniversitenin 2015-2016 eğitim öğretim yılında toplam öğrencisi sayısı 25 047'dir. Üniversitenin açılısı ve nüfus artışı, kentin ekonomisinin ve dolayısıyla da kentin fiziksel olarak canlanmasına yol açmıştır. Geçmiş yıllarda gölden uzak bir alanda konumlanan kent yerleşiminin son zamanlarda kent alanının genişlemesiyle birlikte göl kıyısına doğru yaklaştığı görülmektedir. Bu nedenle, kent şekli de daireselden yol boyu yerleşme özelliği olan ince uzun bir şekle doğru dönüşmektedir. Kent alanının genişlemesi yani nüfusun artması kentin toplam evsel atık miktarının ve su tüketiminin artması sonucunu ortaya çıkarmaktadır. Bu durum da, düşük yağış alan ve kapalı bir havza niteliği gösteren Burdur Gölü Havzası için risk oluşturmaktadır.

\section{Havalimanı}

Burdur Gölü Havzası'nı etkisi altına alan önemli unsurlardan biri de Burdur Gölü'ne çok yakın mesafede ve gölün kuzeydoğusunda konumlanan Süleyman Demirel Havalimanı'dır. Geçmiş yıllarda düzenli uçuş seferleri yapılmayan havalimanında 2015 yılı itibariyle haftanın her günü uçuş seferleri gerçekleştirilmektedir. Bu düzenli uçuşların önemli bir sulak alan niteliğinde olan Burdur Gölü'nde yaşayan ve nesli tükenme tehlikesi altında olan dikkuyruk ördeklerine zarar vereceği düşünülmektedir. Burdur Havalimanına iniş yapan uçakların herhangi bir sebeple göle düşmeleri maddi ve manevi kayıpların yanısıra ekolojik bir felakete neden olacaktır. Ayrıca, Green ve ark., (1996) uçak kaynaklı hidrokarbon ve diğer kirleticilerin göle karışma olasılığının olduğunu rapor etmektedirler.

\section{Mermer Ocakları}

Mermer rezervleri bakımından oldukça zengin olan Burdur'da, plansız ve kontrolsüz şekilde yürütülen mermercilik faaliyetleri havzayı çeşitli açılardan olumsuz etkilemektedir. Mermer ocaklarında su tüketimi fazla olmakta ve bu da yeraltı suyunu dolayısıyla Burdur gölünü tehdit etmektedir. Mermer ocağının işletilmesi sırasında geniş alanlar tahrip edilmektedir. Bundan dolayı da bölgenin ekolojik yapısı ve görselliği değişmektedir. Yine mermer çıkarılma sırasında ortaya çıkan toz bulutları bölge insanının solunum yolu rahatsızlıklarına, çevresindeki bitki örtüsünün yaşam fonksiyonlarının zarar görmesine, bölge toprağında birikme yapması sonucunda tarımsal üretimde ciddi düşüşlere sebep olabilmektedir. Mermercilik faaliyetleri sonucunda oluşan atıklar bölgede geniş alanları işgal etmekte ve görselliği etkilemektedir. Mermer ocaklarının belirli bir alanda çok sayıda olması ve herbirinin belirli büyüklükte bir alanı kaplaması ve herbiri için de hizmet yollarının açılmış olması habitat fragmentasyonlarına da sebep olmaktadır. Özçelik ve ark. (2014) Burdur'da mermer ocaklarının çok olmasının ekosistemlerin bozulmasına, bitki çeşitliliğinin özellikle lokal endemiklerin dağılışının olumsuz etkilenmesine neden olduğunu belirtmişlerdir.

\section{SONUÇLAR}

Çalışmada, Burdur Gölü Havzası'nı tehdit eden başlıca unsurların barajlar, endüstriyel atıklar, tarımsal faaliyetler, kent alanının genişlemesi, havalimanı ve mermer ocakları olduğu anlaşılmıştır. Bu unsurlara ilişkin çözüm önerileri aşağıda maddeler halinde sunulmuştur;

- Barajları yapmadan önce fizibilite raporlarının ciddi şekilde hazırlanması yapılan barajların rasyonelliğini artıracaktır. Yani sadece baraj olsun diye değil, uzun süreli hidrolojik projeksiyonların gerçekleştirilerek barajların susuz kalmaları önlenebilecek ve böylece Burdur gölünün su seviyesinin düşmesinin önüne geçilebilecektir. Barajlarla ilgili sorunların giderilmesi için yapılabilecek diğer bir husus da kurumlar arası yetki karmaşalarının önlenmesidir.

- Ekonomik kaygıları bırakarak, kentteki atık su arıtma tesisinin aktif şekilde çalıştırıması gerekmektedir. Ayrıca, acilen Burdur Organize Sanayi Bölgesi için bir arıtma tesisi inşa edilmelidir. Kentte bulunan Şeker fabrikasının da atıklarını doğrudan göle verip vermediği hususu ilgili kurumlarca dikkatlice izlenmelidir.

- Tarımsal faaliyetlerde damlama sulama sisteminin yaygınlaştırıması çalışmaları hızlandııımalıdır. Bu konuda çiftçilere gerekli bilgilendirmeler sunulmalıdır. Az su tüketen ve daha verimli ıslah edilmiş bitki türlerini yetiştirmeleri konusunda çiftçiler ilgili kurumlarca desteklenmelidir. Ayrıca, bazı araştırmacıların (örneğin Yüksel ve Yüksel, 2011) sunduğu, enerji tasarruflu bilgi ve iletişim teknolojilerinin (RFID Sistemleri, Kablosuz Algılayıcı Ağlar vb.) tarımsal faaliyetlerde etkin kullanımı da sağlanabilir.

- Kent alanının genişlemesi kontrollü ve planlı şekilde gerçekleştirilmelidir. Bu konuda ilgili kurumlar tarafından yeni bir kent alanı oluşturma çalışmaları yapılabilir.

- Havalimanı ile ilgili olarak mümkünse uçakların iniş kalkışlarında göl yüzey alanını kullanmamaları sağlanmalıdır.

- Mermer ocaklarının işletilmesi ile ilgili mevcut yasal düzenlemelerin acilen revize edilmesi ve ek düzenlemelerin gerçekleştirilmesi gerekir. Örneğin, ülkemiz ve bölgeler için mermer ocağı işletmede öncelikli konunun ekoloji mi ya da ekonomi mi olduğu konusunda fikir birliği sağlanmalıdır. Diğer taraftan, bir yerdeki mermercilik faaliyeti sonlandırıldıktan sonra o alanın restorasyon çalışmalarının da tamamlanması yönünde gerekli esasların yasal olarak 
ortaya konması ve uygulanmasının izlenmesi çok büyük önem arz etmektedir.

Yukarıda bahsedilen çözüm önerilerinin uygulanması sırasında ülkenin ve bölgenin sivil toplum kuruluşlarının ve bölge halkının önerilerinin alınması ve bilgilendirilmeleri konularında ilgili kurumlarca büyük bir titizlik gösterilmelidir.

\section{KAYNAKLAR}

Anonim (2009). http://cdr.cevre.gov.tr/icd_raporlari/burduricd2009.pdf.

Anonim (2013). http://www.csb.gov.tr/db/ced/editordosya/Burdur_icdr2013 .pdf.

Anonim (2015). http://bolge9.ormansu.gov.tr.

Ataol, M. (2010). Burdur Gölü'nde Seviye Değisimleri. AÜ TÜCAUM Coğrafi Bilimler Dergisi, 8(1): 77-93.

Çetin, A., Erdoğan, N., Genç, H. (2013). Flora of the Burdur lake surroundings (Türkiye), Biological Diversity and Conservation, 6, 2: 55-76.

DSi (2015). http://www2.dsi.gov.tr/.

Green, A.J. (1996). Threats to Burdur lake ecosystem, Turkey and its waterbirds, particularly the white-headed duck (Oxyura leucocephala). Biological Conservation, 76: 241252.

Güçlü, S.S., Turna, I.I.., Güçlü, Z., Gülle, İ. (2007). Population structure and growth of Aphanius anatoliae sureyanus $\mathrm{Neu} 1937$ (Osteichthyes: Cyprinodontidae), endemic to Burdur Lake, Turkey. Zoology in the Middle East, 41: 6369.

Gül, A., Yılmaztürk, A., Caran, Ş., Ünal, Y., Örücü, Ö.K., Berberoğlu, E. (2015). Burdur Gölü Ve Çevresinde Ekosistem Üzerindeki Çevresel Etkiler Ve Stratejik Mekansal Çözümler. Uluslararası Burdur Deprem ve Çevre Sempozyumu 7-9 Mayıs 2015, Mehmet Akif Ersoy Üniversitesi, BurdurTürkiye.
Gülle, I.., Turna, I.I.., Güçlü, S.S., Küçük, F., Gülle, P., Güçlü, Z. (2008). Burdur Gölü'ndeki Sıcaklık, Çözünmüş Oksijen, $\mathrm{pH}$ ve Elektriksel İletkenlik Değerlerinin Dikey Yönde Değişimi, E.Ü. Su Ürünleri Dergisi, 25(4): 283-287.

Karataş, A. (2013). Burdur Gölü Havzası'nın biyotik özellikleri ile mermer ve taş ocaklarını Burdur Gölü ve ekosistem üzerine etkileri, Niğde Üniv. Fen Edb. Fakültesi Biyoloji Böl., Niğde.

Kiziroğlu, İ., Turan, L. ve Erdoğan, A. (1995). Burdur Gölü Havzasının Entegre Koruma ve Kullanım Planlaması Üzerine Bir Araştırma. Hacettepe Üniv. Eğt. Fak. Dergisi, 11: 37-45.

Küçük, F., Gülle, İ., Güçlü, S.S., Çiftçi, Y., Erdoğan, Ö. (2013). A new Pseudophoxinus (Teleostei, Cyprinidae) species from Southwestern Anatolia, with remarks on the distribution of the genus in western Anatolia. ZooKeys, 320: $29-41$

Özçelik, H., Çinbilgel, İ., Koca, A., Muca, B. (2014). Mermer Ocaklarının Burdur Florası Üzerine Etkileri. Ulusal Mermer Ve Taş Ocakları Onarım Teknikleri Sempozyumu, 1820 Eylül 2014, Isparta

Yıldırım, Ü., Uysal, M. (2011). Changes in the Coastline of the Burdur Lake Between 1975 and 2010. International Symposium on Environmental Protection and Planning: Geographic Information Systems (GIS) and Remote Sensing (RS) Applications (ISEPP) 28-29 June 2011, IzmirTurkey.

Yiğitbaşıoğlu, H., Uğur, A. (2005). Burdur Gölü'nün Jeoekolojik Özellikleri ve Sorunları. Türkiye Kuvaterner Sempozyumu V Bildiri Özetleri, İstanbul, 100-1003.

Yiğitbaşıoğlu, H., Uğur, A. (2006). Sulak Alanlarımız ve Ramsar Sözlesmesi. Popüler Bilim, 32: 43-46.

Yiğitbaşıoğlu, H., Uğur, A. (2010). Burdur Gölü Havzasında Arazi Kullanım Özelliklerinden Kaynaklanan Çevre Sorunları. Ankara Üniversitesi Çevrebilimleri Dergisi, 2(2): 129143.

Yüksel, M. E., Yüksel A.S. (2011). RFID Technology in Business Systems and Supply Chain Management. Journal of Economic and Social Studies (JECOSS), 1(1): 53-71. 